Gut, 1988, 29, 826-829

\title{
Ranitidine and oxygen derived free radical scavengers in haemorrhagic shock induced gastric lesions
}

\author{
E C TSIMOYIANNIS, C J SARROS, J C TSIMOYIANNIS, K MOUTESIDOU, \\ G AKALESTOS, AND O B KOTOULAS \\ From the Department of Surgery, G Hatzikosta General Hospital of Ioannina and Department of Anatomy, \\ Ioannina University Medical School, Ioannina, Greece
}

SUMmary The role of oxygen derived free radicals in gastric lesions induced by haemorrhagic shock and the protective effect of oxygen radical scavengers, allopurinol and ranitidine, were investigated. Forty five rabbits underwent haemorrhagic shock for 30 minutes and reinfusion of shed blood. They were killed 30 minutes later. The animals were divided in five groups: $A(n=10)$ : Control, B $(n=10)$ : intravenous ranitidine pretreatment, $C(n=10)$ : oral allopurinol, 24 and $2 \mathrm{~h}$ before surgery, $D(n=10)$ : intravenous pretreatment with superoxide Dismutase plus catalase, $E$ $(n=5)$ : 60 minute haemorrhagic shock without reinfusion and treatment. Erosions and/or petechiae in all animals in Group $A$ were observed. Three animals in group B and $C$ and 2 in group D $(p<0.005, p<0.001)$ had gastric lesions. The lesions in the pretreatment groups were significantly smaller than in controls. Oxygen radicals plus $\mathrm{HCl}$ play an important role in shock induced gastric lesions. Oxygen radical antagonists show a significant protective role.

Clinical and experimental studies have shown that haemorrhagic shock often is followed by rapid development of gastric mucosal lesions. ${ }^{1-3}$ Gastric blood flow is considerably reduced during haemorrhagic shock. In the fundic mucosa the reduction of blood flow is more extensive than in the antral mucosa. ${ }^{+}$A number of hypotheses have been proposed to explain the mechanism of ischaemia induced gastric lesions, but the pathogenesis remains uncertain. ${ }^{2-7}$

Recent evidence suggests that oxygen derived free radicals may be abundantly produced in postischaemic tissues, accounting for at least part of the damage.: Furthermore, it has been reported that superoxide radicals $\left(\cdot 0_{2}^{-}\right)$play an important role in the formation of gastric lesions produced by ischaemia plus $\mathrm{HCl} .{ }^{9} \mathrm{Hydroxyl}$ radical $\left(\mathrm{OH}^{\prime}\right)$ appears to be the major oxygen radical contributing to ischaemic damage of gastric musoca. ${ }^{11}$

The present experiments were designed to study

Address for correspondence: Evangelos ( Tsimoyiannis. MI). Stavraki of loannina, 45500 Ioannina, Greece.

Received for publication 12 January 1988 the role of oxygen derived free radicals in haemorrhagic shock induced gastric lesions and the protective effect of oxygen radical scavengers, allopurinol (a xanthine oxidase inhibitor) and ranitidine (an $\mathrm{H}_{2}$ receptor antagonist), in the rabbit stomach.

\section{Methods}

ANIMALS

Forty five female white rabbits weighing 1200 $2000 \mathrm{~g}$, were fasted for 24 hours before the experiments but were allowed water ad libitum. Each animal was anaesthetised with ketamine $(50 \mathrm{mg} / \mathrm{kg}$ body weight $)$ plus fentanyl $(0 \cdot 025 \mathrm{mg} / \mathrm{kg})$ and diazepam $(5 \mathrm{mg} / \mathrm{kg})$. External jugular vein was catheterised for the administration of the drugs. Carotid artery was canulated using a 22 gauge catheter. Another 22 gauge catheter was inserted into the femoral artery in order to withdraw and reinfuse blood. Laparotomy was undertaken and the gastroesophageal junction and duodenum $(2 \mathrm{~cm}$ distal to the pylorus) were ligated. A small gastrotomy was carried out at the greater curvature of the rumen and a tube was passed through the gastrotomy for gastric 


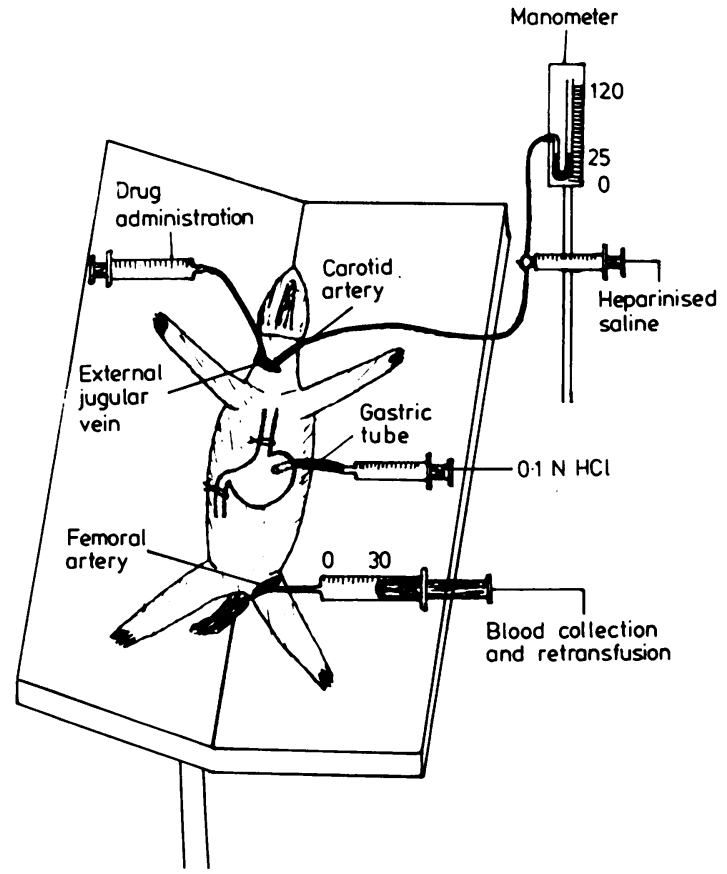

Figure Schematic representation of the experimental model.

lumen lavage (Figure). One millilitre $0 \cdot 1 \mathrm{~N} \mathrm{HCl} / 100 \mathrm{~g}$ body weight ${ }^{9}$ was instilled into the stomach through the gastric tube. The tube was then removed and the gastrotomy was sutured with Vicryl No 4/0. Blood was withdrawn from the femoral artery into a syringe containing $1.5 \mathrm{ml}$ heparinised saline (100 U heparin/ $\mathrm{ml})$ until the mean blood pressure was reduced to $20-30 \mathrm{mmHg}$. The blood pressure was maintained at this level for $30 \mathrm{~min}$, the shed blood was then reinfused. Thirty minutes later the animal was killed by decapitation and the stomach was removed. The $\mathrm{pH}$ of the gastric juice was determined at the end of the shock period and the end of the experiment. The stomach was opened along the greater curvative and the gastric mucosal lesions were identified using a dissecting microscope with $\times 25$ magnification. The area of the gastric lesions was measured in $\mathrm{mm}^{2}$ as previously described. ${ }^{y}$ The stomach was then fixed in $7 \%$ formalin.

Five groups of rabbits have been included in this study. The drug pretreatment regimens were as follows: group A $(n=10)$ : no pretreatment (control group); group $B(n=10)$ ranitidine $1 \mathrm{mg} / \mathrm{kg}$ intravenously through the jugular vein as bolus $15 \mathrm{~min}$ before the removal of blood; group $C(n=10)$ : allopurinol $50 \mathrm{mg} / \mathrm{kg}$ orally through an oragastric tube, 24 and two hours before surgery; group D
Table 1 Mean blood pressure (mean (SD)) before and during the shock and retransfusion periods

\begin{tabular}{|c|c|c|c|c|}
\hline \multirow[b]{2}{*}{ Group } & \multirow[b]{2}{*}{$n$} & \multicolumn{3}{|c|}{ Blood pressure $(\mathrm{mmHg})$} \\
\hline & & Prebleeding & Postbleeding & Postreinfusion \\
\hline A & 10 & $118 \cdot 1(17 \cdot 3)$ & $24.9(1.8)$ & $117 \cdot 5(15 \cdot 5)$ \\
\hline B & 10 & $114.6(22.8)$ & $25 \cdot 0(1 \cdot 6)$ & $110.0(10.5)$ \\
\hline C & 10 & $107 \cdot 4(19 \cdot 4)$ & $24.9(1.7)$ & $109 \cdot 0(10 \cdot 1)$ \\
\hline D & 10 & $117 \cdot 0(9 \cdot 2)$ & $25 \cdot 0(1 \cdot 6)$ & $116 \cdot 0(6 \cdot 5)$ \\
\hline E & 5 & $129 \cdot 2(14 \cdot 3)$ & $24.8(1.9)$ & - \\
\hline
\end{tabular}

$(\mathrm{n}=10):$ superoxide dismutase plus catalase, each $15000 \mathrm{U} / \mathrm{kg}$ iv through the jugular vein as bolus immediately before induction of shock; group $E(n=$ $5)$ : no pretreatment. Sixty minute haemorrhagic shock without reinfusion of the blood.

STATISTICAL ANALYSIS

Student's $t$, Hodges-Lehman (non-parametic procedure) and $\chi^{2}$ tests were used to analyse the data.

\section{Results}

The removal of about $19 \mathrm{ml} / \mathrm{kg}$ body weight of blood caused a profound decrease in the arterial pressure of the animals. The pressure almost returned to baseline values after restoration of the normal blood volume (Table 1).

The gastric juice $\mathrm{pH}$ was about 1.0 in all groups after the instillation of $0 \cdot 1 \mathrm{~N} \mathrm{HCl}$. No change of $\mathrm{pH}$ was present after a 30 minute haemorrhagic shock period. At the end of the experiment, 30 minutes after the reinfusion of shed blood, a statistically significant increase of gastric juice $\mathrm{pH}$ of group $\mathrm{B} v$ group A was noted (Table 2).

In the control group (group A), all animals showed gastric mucosal erosions and/or petechiae. Statistically significant decrease of the incidence and severity of gastric mucosal lesions was presented in all pretreatment groups (Table 3 ). In the animals of group A the formation of mucosal lesions occurred

Table 2 Values of gastric juice pH (mean (SD))

\begin{tabular}{|c|c|c|c|}
\hline \multirow[b]{2}{*}{ Group } & \multicolumn{3}{|c|}{ Gastric juice pH } \\
\hline & Prebleeding & $\begin{array}{l}\text { At the end of } \\
\text { the shock }\end{array}$ & $\begin{array}{l}\text { At the end of } \\
\text { the experiment }\end{array}$ \\
\hline A & $1 \cdot 06(0 \cdot 06)$ & $1 \cdot 07(0 \cdot 05)$ & $1 \cdot 50(0 \cdot 25)$ \\
\hline B & $1 \cdot 05(0 \cdot(07)$ & $1 \cdot 05(0 \cdot 06)$ & $2.43(0 \cdot 65)^{*}$ \\
\hline $\mathrm{C}$ & $1 \cdot 03(0 \cdot 06)$ & $1 \cdot 06(0 \cdot 05)$ & $1.93(0.80)$ \\
\hline D & $1 \cdot 06(0 \cdot 05)$ & $1 \cdot 08(0 \cdot 06)$ & $1 \cdot 40(0 \cdot 34)$ \\
\hline $\mathrm{E}$ & $1 \cdot 02(0 \cdot(04)$ & - & $1 \cdot(04(0 \cdot 05)$ \\
\hline
\end{tabular}

${ }^{*} \mathrm{p}<0.01 v$ group A (control) at the same period ( $t$ test). 
Table 3 Incidence and total lesion area after haemorrhagic shock and retransfusion-induced gastric lesion

\begin{tabular}{lcll}
\hline & & $\begin{array}{l}\text { Rabbits } \\
\text { with gastric } \\
\text { lesions }(n)\end{array}$ & $\begin{array}{l}\text { Total lesion area in } \mathrm{mm}^{2} \\
(\text { mean }(S D))\end{array}$ \\
\hline A & $n$ & 10 & $86 \cdot 6(54 \cdot 4)$ \\
B & 10 & $3^{*}$ & $10 \cdot 1(28 \cdot 2) \S$ \\
C & 10 & $3 \dagger$ & $20 \cdot 6(56 \cdot 4) \|$ \\
D & 10 & $2 \ddagger$ & $7 \cdot 5(22 \cdot 0) \emptyset$ \\
E & 10 & 0 & - \\
\hline
\end{tabular}

${ }^{*} \mathrm{p}<0.005 v$ group $\mathrm{A}$ using $\chi^{2}$ test $; \dagger \mathrm{p}<0.005 v$ group $\mathrm{A}$ using $\chi^{2}$ test; $\ddagger \mathrm{p}<0 .\left(001 v\right.$ group A using $\chi^{2}$ test; $\left.\$ \mathrm{p}<0.000\right) 5, \mathrm{x}^{2}=12 \cdot 1 v$ group $\mathrm{A}$ using Hodges-Lehman test; $\| \mathrm{p}<0 \cdot 0026, \chi^{2}=9 \cdot(07 v$ group $\mathrm{A}$ using Hodges-Lehman test $:$ p $<0 \cdot 00\left(044, \chi^{2}=12.4 v\right.$ group A using Hodges-Lehman test.

mainly in the corpus. The total area of the gastric lesions was $86 \cdot 6(54.4) \mathrm{mm} .^{2}$ Values are expressed as mean (SD). Only in one animal lesions were found in the duodenum $\left(30 \mathrm{~mm}^{2}\right)$. In another animal lesions were found in the antrum $\left(45 \mathrm{~mm}^{2}\right)$. Significant decrease of the total lesion area was presented in the pretreatment groups (Table 3 ).

The animals in group E died 40-50 minutes after the blood withdrawal. No change of gastric juice $\mathrm{pH}$ was found. None of the animals developed gastric mucosal lesions.

The presence of mucosal lesions was confirmed by histological examination. The microscopic examination of the erosions revealed a loss of the superficial layers (lining epithelium and gastric pits) and a destruction of the normal architecture of the upper part of the gastric mucosa. Intact cells of the gastric glands could still be observed but the normal parallel arrangement of the cellular elements of the glands could not be detected at the upper part of the mucosa. Marked congestion of the mucosa and small subepithelial haemorrhagic areas were frequently found at or near the erosions.

\section{Discussion}

In the present study a 30 minute period of haemorrhagic shock followed by a 30 minute period of reinfusion of the shed blood led to the appearance of mucosal lesions mainly in the corpus of the stomach. This topographical predilection could be explained on the basis of a higher susceptibility of the corpus to the haemorrhagic shock. This may be because of the greater degree of circulatory disturbance and the higher vulnerability to ischaemia of this region. "In anaesthetised dogs during the shock, the blood flow to fundic mucosa decreases more extensively than the flow to antral mucosa. ${ }^{4}$

Gastric mucosal permeability to the back diffusion of hydrogen ion is increased by many chemical agents. ${ }^{62}$ A short period of haemorrhagic shock (40 mmHg mean arterial pressure for 15 minutes) had a disruptive effect on the gastric mucosal barrier to the hydrogen ion. This effect is similar to that produced by certain chemical agents. ${ }^{\circ}$ Gastric acid is an indispensable factor in the pathogenesis of gastric lesion formation. Acid induces the formation and extension of gastric mucosal injury in circumstances in which the gastric mucosa is initially damaged by other factors." In our experiments, pretreatment with ranitidine, an $\mathrm{H}_{2}$ receptor antagonist, significantly decreased the gastric mucosal lesions. At the end of the experiment there were some increase in the level of $\mathrm{pH}$ in the reinfused groups, except group B, but the difference was not statistically significant. In ranitidine group (group B) a statistically significant increase of $\mathrm{pH}$ was noted. It is known that $0 \cdot 1 \mathrm{~N} \mathrm{HCl}$ alone does not produce mucosal injury. ${ }^{4}$

Prolonged ischaemia followed by reperfusion produces morphological alterations of the tissues including endothelial cell swelling, interstitial oedema and necrosis. ${ }^{1314}$ Haemorrhagic shock may be viewed as a "whole body ischemia'. All the tissues may be insufficiently perfused. During the shock, ATP concentrations are drastically reduced in many organs ${ }^{15}$ resulting in raised hypoxanthine concentrations in plasma. ${ }^{1617}$ Reconstitution of the intravascular volume fully restores' microvascular perfusion and tissue oxygenation, setting the stage for a reperfusion injury. In the renewed presence of molecular oxygen, xanthine oxidase reacts with hypoxanthine to produce the cytotoxic superoxide radical $\left(\cdot \mathrm{O}_{2}^{-}\right)$:

$$
\text { Hypoxanthine }+\mathrm{O}_{2} \stackrel{\text { xanthine }}{\text { oxidase }} \longrightarrow \text { Xanthine }+\cdot \mathrm{O}_{2}^{-}
$$

Superoxide dismutase efficiently and specifically scavenge the superoxide radical by catalysing its dismutation to hydrogen peroxide and oxygen: ${ }^{18}$

$$
\begin{gathered}
\text { superoxide } \\
\cdot \mathrm{O}_{2}^{-}+\cdot \mathrm{O}_{2}^{-}+2 \mathrm{H}^{+} \stackrel{\text { dismutase }}{\longrightarrow} \mathrm{H}_{2} \mathrm{O}_{2}+\mathrm{O}_{2}
\end{gathered}
$$

Hydrogen peroxide which is a relatively non-toxic substance can be scavenged by catalase to form water and molecular oxygen: ${ }^{1 \times}$

$$
\mathrm{H}_{2} \mathrm{O}_{2}+\mathrm{H}_{2} \mathrm{O}_{2} \stackrel{\text { catalase }}{\longrightarrow} 2 \mathrm{H}_{2} \mathrm{O}+\mathrm{O}_{2}
$$

Evidence to support this hypothesis is provided by the observation that allopurinol substantially increased the survival rate of dogs subjected to haemorrhagic shock. ${ }^{16}{ }^{19}$ Recent studies suggest that oxygen derived free radicals play an important role in the formation of gastric lesions produced by ischemia plus $\mathrm{HCl} .{ }^{911}$ Particularly $\cdot \mathrm{O}_{2}^{-}$in the rat stomach or $\mathrm{OH}^{*}$ in the cat stomach ${ }^{11}$ appear to be the major oxygen radicals contributing to ischaemic damage. 
In the present study superoxide dismutase, a $\cdot \mathrm{O}_{2}^{-}$scavenger, plus catalase, an $\mathrm{H}_{2} \mathrm{O}_{2}$ scavenger, significantly decreased gastric lesion formation induced by haemorrhagic ischaemia. Allopurinol, a xanthine oxidase inhibitor, significantly decreased gastric lesion formation as well. These drugs, allopurinol and free radical scavengers, had the same protective effect on the gastric mucosa as ranitidine, an $\mathrm{H}_{2}$ receptor antagonist. The $\mathrm{H}_{2}$ receptor antagonists are well known and effective drugs for prevention and treatment of stress ulcers. . $^{2121}$

In conclusion, the findings of the present study suggest that oxygen derived free radicals play an important pathogenetic role in the haemorrhagic shock induced gastric mucosal lesions in the rabbit stomach. Oxygen radicals and $\mathrm{HCl}$ have about the same injurious effect in the gastric mucosa, while both are needed to produce the mucosal injury. Antagonists of oxygen radicals or $\mathrm{HCl}$ play a significant protective role against the haemorrhagic shock induced stress ulcers.

\section{References}

1 Godman AA, Frey CF. Massive upper gastrointestinal hemmorrhage following surgical operations. Ann Surg 1968; 167: 180-4.

2 Harjola P-T, Sivula A. Gastric ulceration following experimentally induced hypoxia and hemorrhagic shock: In vivo study of pathogenesis in rabbits. Ann Surg 1966; 163: 21-8.

3 Menguy R, Masters YF. Gastric mucosal energy metabolism and 'stress ulceration'. Ann Surg 1974; 180: 538-48.

4 Shirazi SS, Mueller TM, Hardy BM. Canine gastric acid secretion and blood flow measurement in hemorrhagic shock. Gastroenterology 1977: 73: 75-81.

5 Sales J, Norton L, Nolan P, Rankin J, Eiseman B. Gastric mucosal ischemia in experimental stress ulcer. $J$ Surg Res 1975; 18: 65-74.

6 Skillman JJ, Gould SA, Chung RSK, Silen W. The gastric mucosal barrier: Clinical and experimental studies in critically ill and normal man and in the rabbit. Ann Surg 1970); 172: 564-84.

7 Menguy R, Desbaillets L, Masters YF. Mechanism of stress ulcer: Influence of hypovolemic shock on energy metabolism in the gastric mucosa. Gastroenterology 1974; 66: 46-55.

8 McCord JM. Oxygen-derived free radicals in postischemic tissue injury. $N$ Engl J Med 1985; 312: 159-6.3.

9 Itoh M, Guth PH. Role of oxygen-derived free radicals in hemorrhagic shock-induced gastric lesions in the rat. Gastroenterology 1985; 88: 1162-7.

10 Perry MA, Wadhwa S, Parks DA, Pickard W, Granger DN. Role of oxygen radicals in ischemia-induced lesions in the cat stomach. Gastroenterology 1986; 90: 362-7.

11 Manabe T, Suzuki T, Honjo I. Changes of upper gastrointestinal blood flow after hemorrhage in rabbits. Surgery 1977; 81: 446-52.

12 Davenport HW. Gastric mucosal injury by fatty and acetylsalicylic acids. Gastroenterology 1964; 46: 245-9.

13 Strock E, Majno G. Microvascular changes in acutely ischemic rat muscle. Surg Gynecol Obstet 1969; 129: 1213-24.

14 Burton KP, McCord JM, Ghai G. Myocardial alterations due to free radical generation. Am J Physiol 1984; 246: H776-83.

15 Cunningham SK, Keaveny TV. Splanchnic organ adenine nucleotides and their metabolites in hemorrhagic shock. Ir J Med Sci 1977; 146: 136-43.

16 Jones CE, Crowell JW, Smith EE. Significance of increased blood uric acid following extensive hemorrhage. Am J Physiol 1968; 214: 1374-7.

17 Brawn K. Fridovich I. Superoxide radical and superoxide dismutase. Acta Physiol Scand 1980; 492: suppl: 9-18.

18 Fridovich I: The biology of oxygen radicals. Science 1978; 201: 875-80.

19 Crowell JW, Jones CE, Smith EE. Effect of allopurinol on hemorrhagic shock. Am J Pyhsiol 1969; 216: 744-8.

20 Levine BA, Sirinek KR, McLeod CG, Teegarden DK, Pruitt BA. The role of Cimetidine in the prevention of stress induced gastric mucosal injury. Surg Gynecol Obstet 1979; 148: 399-402.

21 Solem LD, Strate RG, Fischer RP. Antacid therapy and nutritional supplementation in the prevention of Curling's ulcer. Surg Gynecol Obstet 1979; 148: 367-70. 